\title{
Factors Influencing Information Delivery Technology Choice by Women in Deprived Regions in Ghana
}

\author{
Olivia Kwapong \\ Harvard University / University of Ghana \\ $<$ okwapong@ug.edu.gh $>$
}

\begin{abstract}
Using a contingent valuation (CV) method to quantitatively estimate the influence of selected socioeconomic factors on households' willingness to pay for alternative information delivery technologies, the study intended to provide basic information regarding rural households' willingness to pay for information delivery technologies.

This study used rural household survey data collected from three administrative regions in Ghana to examine rural women's willingness to pay for information delivered via three technologies community radio, private radio, and extension agents.

The primary objective of the study was to identify the critical factors to consider in planning and policy design in using ICT to provide information to empower rural women. While there were nontrivial regional variations, the overall results from this study point to household expenditures (used as proxy for income), household education, and membership in community organizations as the principal factors influencing rural women's willingness to pay for the various technologies used in information delivery to women in rural areas in Ghana. The overriding conclusion that emerged from this study was the need to examine ICT use in empowering rural women within a 'holistic' context.
\end{abstract}

\section{Introduction}

There is broad consensus that ICT could play an important role to make development effective on a large scale for disadvantaged people. As pointed out by the UN Secretary-General Kofi Annan, "Over the last few years, a wide consensus has emerged on the potential of information and communications technologies (ICT) to promote economic growth, combat poverty, and facilitate the integration of developing countries into the global economy. Seizing the opportunities of the digital revolution is one of the most pressing challenges we face" (Annan, 2002).

Ghana has responded to the ICT challenge. In 2003, Ghana announced the Ghana Integrated ICT for Accelerated Development (ICT4AD) Policy, which summarized the vision of Ghana in the information age. While the policy outlines a broad array of objectives, it is clear that the core of the policy is to use ICT to achieve Ghana's vision of becoming a middle-income country by the year 2020. Despite the wide recognition of the role of ICT in national development, the development of a successful ICT program to accelerate empowerment of women in Ghana is beset by several institutional, technical, political, economic and social problems.

Probably the most daunting task facing policy makers in Ghana is making ICT available to the poorest population segments in the face of tight government budgets. ICT policies and programs are expensive to design and implement. Resources are needed for infrastructure and operational purposes. Given the pressure on the government's budget, it may be necessary to solicit contributions from rural households, a rather difficult proposition given household income levels in the poorest rural areas. Furthermore ICT use depends on the socio-economic characteristics of rural households. Yet the ongoing policy debate concerning ICT in empowering rural households seems tilted to the belief that all Ghana needs is to make ICT available and rural households will jump at the opportunity. A credible and sustainable ICT policy to empower women in rural Ghana should consider the socio-economic characteristics of households, including a determination of their willingness to pay for alternative ICT technologies.

This study uses a contingent valuation (CV) method to quantitatively estimate the influence of selected socio-economic factors on households' willingness to pay for alternative information delivery technologies. CV methods have been applied to several public goods valuations in developing countries. For example, Thobani (1983) and Tan et. al. (1984) used the approach to study payments for education services; Boadu (1993) for rural water supply and Haba (2004) for rural information services. Even though the method does not answer several important questions including ability to pay and equity concerns, it has been widely regarded as a useful tool to help planners gain some understanding in establishing basic financing guidelines in the provision of public goods. This study is intended to provide basic 
information regarding rural female households' willingness to pay for information delivery technologies.

\section{Study Areas and Research Procedures}

The basic document summarizing the state of poverty in Ghana, identifying strategies to defeat poverty, targets, constraints, and projections is the Ghana Poverty Reduction Strategy paper (GPRS, 2003). According to the GPRS, five out of ten regions had more than $40 \%$ of their population living in poverty in 1999. The three northern regions (Upper East, Upper West and Northern Regions) are the hardest hit with nine out of ten people in the Upper East; eight out of ten people in the Upper West, and seven out of ten people in the Northern Regions classified as poor in 1999 (GPRS 2003: ii). This study is based on survey data from the three northern regions in Ghana. In addition to being the hardest hit poverty areas, there is a general lack of communication infrastructure and low economic activity.

The data used in this study was based on a contingent valuation survey instrument developed by the author and administered in several villages in Ghana . The survey was divided into two main parts. The first part sought information on basic characteristics of households (age, education, dependents, occupation, expenditures, and membership in community organizations). The second part consisted of a bidding game for alternative information delivery technologies. Three main information delivery technologies were considered - community radio, private radio, and extension agents who use printed materials to disseminate information. The main distinguishing feature of these technologies was price.

The use of radio in rural communication is very common in Sub-Sahara Africa (SSA). The proposed framework considers radio technology as a key information delivery instrument given its popularity. Ghana has one of the highest radio ownership rates in SSA (710 per 1,000 people in 2002) compared to an ownership rate of 198 per 1,000 people in the rest of SSA, and 139 per 1,000 people for all low income countries. Ghana's ownership rate represents about a 207 percent increase over a 7-year period, 1995-2002 (World Bank, 2003). Following the approach used in several studies, information dissemination through the radio is considered in two contexts - private radio and community radio (Boadu, 1993; Haba, 2004; Abbey-Mensah, 2001). There are good reasons to consider radio use in these two contexts. Governments and donors who usually fund the rural education programs may want to reduce the cost of information dissemination by increasing the number of radio listeners usually in a group format. In the group format, the amount of contribution to be made by information recipients is correspondingly reduced. The reduced cost make households more willing to pay for the information that is disseminated through the community radio format. An added benefit of a community radio format is the opportunity for listeners to interact and react to information received taking into account the views and opinions of other receivers of information. This interaction enriches the learning process and may be preferred by households.

On the other hand, there may be some rural households that prefer their own private radio to receive information. It is plausible that younger and educated females may want to have the freedom to listen to other radio programs (for example, broadcasts in English), and therefore will be more willing to pay for their own radio instead of paying for a community radio. It is also very likely that educated rural dwellers have higher incomes since they may draw income from both farm and non-farm sources. In this context, they will be in a position to pay for their own radio sets to receive information.

In terms of print media to be distributed by extension agents, the focus of the study is on extension bulletins and adult education publications. The extension and adult education publications are assumed to be part of a person-to-person information delivery protocol. Information through the print media is delivered by extension agents. There is no consideration of newspapers given the currently low level of newspaper circulation in the region, about 14 per 1000 population in 2001 compared to about 40 per 1000 population for low-income countries for the same period (World Bank, 2003).

The preceding suggests that the study considers information delivery by community radio to be the cheapest since several households contribute to the purchase and maintenance of the system. Extension agents are considered the next cheapest of the three technologies considered because the government pays these agents. The idea is to explore the extent to which a part of the cost of extension information delivery could be shifted to households and lessen the burden on government. The most expensive delivery technology is the private radio since a household owns it individually and pays the full amount for it.

Bidding took the form of a series of specific questions. For example, a respondent was asked whether she would be willing to pay $\phi 1,000$ (one thousand Ghana cedis, approximately US\$ 0.10 ) per year to use a community radio. If 'yes' the question was posed again with an increase in the amount to $\not 2,000$ (approximately US\$0.20). The process continued until there a 'No' answer was given. The final amount to which the respondent answered 'yes' was recorded as the maximum the individual was willing to pay to have the community radio installed in the village. For extension agents, the beginning bid was at $\phi 5,000$ (approximately US $\$ 0.50$ ), while for private radios, the beginning point was $\phi 10,000$ (approximately US\$1.00). Respondents were also given the opportunity to state an amount they would be willing to pay for each of the information delivery technologies.

Field data was collected with the assistance of Regional Officers of the local Institute of Adult Education. These 
Officers are located in the Regional Centers of the Institute, which is established in all the ten regions of Ghana and are constantly engaged in community programs with the local people. These field officers were recruited for this survey because they are in partnership with the community members and over time they have won the confidence and trust of the rural households. They have established mutual working relationship with the women in the local communities. They also have good knowledge of the regional demographics and are able to communicate in the language that the people understand. Their accumulated community research and training experience, residence in the regions and effort helped ensure a rapid field data collection.

Data was collected in a face-to-face interview where the interviewer had the opportunity to explain the purpose of the survey and the need to obtain truthful responses from the respondents. Based on their familiarity with the communities, experiences and training the interviewers understood the need to conduct the interview in a manner that did not impair the integrity of the effort. As a strategy, they interviewed the female household head in every other house. Respondents were also cautioned not to discuss their responses with other households. There was broad agreement among field staff that respondents took the process seriously and were willing to offer truthful information to assist in achieving the objectives of the survey.

Table 1 lists the means of selected independent variables used in the study and also the mean bids for private radio, community radio, and extension service information agents. The table also presents mean measures for selected variables based on the Ghana Living Standards Survey 4 (GLSS, 2000).

Table 1. Means of Independent Variables Compared to Means from GLSS 4

\begin{tabular}{|l|l|l|l|l|l|l|}
\hline \multicolumn{5}{|l|}{ Household Bids in Ghana Cedis } & & \multicolumn{2}{l|}{} \\
\hline Region & $\begin{array}{l}\text { Extension } \\
\text { Information }\end{array}$ & $\begin{array}{l}\text { Community } \\
\text { Radio }\end{array}$ & $\begin{array}{l}\text { Private } \\
\text { Radio }\end{array}$ & $\begin{array}{l}\text { No. of } \\
\text { Dependents }\end{array}$ & $\begin{array}{l}\text { Expenditure } \\
\text { Survey }\end{array}$ & $\begin{array}{l}\text { Expenditure } \\
\text { GLSS 4 }\end{array}$ \\
\hline Western & 6182 & 3535.5 & 10404 & 2.79 & $5,0525,25$ & $4,677,000$ \\
\hline Central & 10180 & 3886 & 22450 & 3.74 & $5,153,510$ & $2,977,000$ \\
\hline Gt. Accra & 10202 & 3656 & 21162 & 2.83 & $11,495,487$ & $6,777,000$ \\
\hline Volta & 7320 & 5200 & 11190 & 2.39 & $6,134,540$ & $4,000,000$ \\
\hline Eastern & 8909 & 4868 & 22696 & 3.33 & $8,549,222$ & $3,736,000$ \\
\hline Ashanti & 8480 & 3360 & 22300 & 3.61 & 11054650 & $5,008,000$ \\
\hline B. Ahafo & 10030 & 3730 & 24305 & 1.77 & $4,180,710$ & $3,544,000$ \\
\hline Northern & 9520 & 3400 & 21069 & 4.43 & $3,335,400$ & $2,837,000$ \\
\hline Upp. West & 9980 & 3830 & 26200 & 5.67 & $2,070,160$ & $2,462,000$ \\
\hline Upp. East & 8595 & 3141 & 21262 & 3.04 & $4,059,460$ & $1,793,000$ \\
\hline
\end{tabular}

Consistent with expectations, mean bids for private radio is highest, followed by mean bids for extension information, followed by community radio. The means are sufficiently credible to provide a reasonable basis for the survey data analysis.

\section{Model and Statistical Estimation}

A multiple linear regression relationship was assumed between the dependent variable and the independent variables. The following factors were hypothesized to influence a household's willingness to pay for a selected technology: 


\section{Income:}

It is difficult to predict the effect of income on the willingness to pay for ICT in rural households. Generally, a positive relationship between income and the willingness to pay for ICT is expected. Households with high incomes tend to spend a smaller proportion of income on food while poorer households spend a higher proportion of income on food. Thus, one would expect the effect of income on ICT choice to be positive in the relatively richer regions. Furthermore, one would expect households with high incomes to use private radios instead of community radios in receiving information. One could argue that even though poorer households spend a higher proportion of income on food, their interest in obtaining information to 'kick' out poverty may encourage them to be willing to pay for ICT information.

In practice though, there are no statistically significant differences in households' willingness to pay across regions. In this sense, it is difficult to predict the exact sign (positive or negative) on the income variable, and the issue is left to empirical determination. An indirect approach was used to obtain measures of income from rural households. Households were asked to list their major sources of income, and then inquired about their expenditure patterns. This was done due to the difficulty in obtaining direct income figures from households and also to capture the effect of transfers. These expenditure amounts were used as proxies for income. Rural savings is very low. The GLSS found that only about $13 \%$ of rural dwellers maintained any savings account so the expenditure figures are a plausible measure of the household financial situation in a given year. Indeed studies of willingness to pay for amenities in rural households have found direct rural income measures to be unreliable and have resorted to proxies to estimate income (Boadu, 1993).

\section{Education:}

Rural females have lower school attendance rates across all regions with the lowest rates recorded in the three northern regions (Northern, Upper West and Upper East). Generally, it is hypothesized that educated households will be willing to pay for any ICT media given the premium on information in decision making. While an illiterate household naturally would depend on the radio and extension visits for information, a literate household has the additional source of information delivered through extension bulletins, and other printed sources.

\section{Age:}

It is hypothesized that older households will be more willing to pay for community radio systems and extension visits. There are good reasons for this expectation. First, older households are likely to belong to community organizations and hence more comfortable with sharing the media. On the other hand, a young household is also likely to be less involved in community organizations, and may be more willing to pay for their own private radio system.

\section{Marital Status:}

The combined income effect of married couples is likely to encourage their willingness to pay for private radio information delivery technology. Oftentimes community organization activities are organized along gender lines and there is not much joint community activities between men and women. Thus, information delivery via community radio or extension services would be less attractive to married households. A plausible hypothesis is that married households will be more likely to pay for private radio, and are unlikely to pay for extension information or community radio.

\section{Household Size:}

The household is defined to include all persons who are under the direct responsibility of the female respondent. At a given income level, large households are less likely to pay for private radios given the cost of these radios. Thus, large households will be more willing to pay for community radios and extension services, while small households are more likely to be willing to pay for private radios.

\section{Membership in Community Organizations:}

It is hypothesized that households that belong to a community organization will be willing to pay for information delivered via community radio. Community radio is cheaper than a private radio and more importantly, these households have cultivated the spirit of sharing through their membership in an organization. Table 2 shows that rural households make more contribution to community initiatives than do urban households. By analogy, it is hypothesized that households in the more deprived areas, especially in the northern regions will be more willing to pay for community radio and extension services compared to those rural communities located near the urbanized regions in Ghana such as Accra, Kumasi (Ashanti), Takoradi (Western), and Cape Coast (Central).

\section{Table 2. Miscellaneous Expenditures by Urban and Rural Households}




\begin{tabular}{|c|c|c|c|c|}
\hline \multirow[b]{3}{*}{ Purpose of expenditure } & \multicolumn{3}{|c|}{ Mean household expenditure } & \multirow{3}{*}{\begin{tabular}{|l}
$\begin{array}{l}\text { Estimated total } \\
\text { miscellaneous } \\
\text { expenditure }\end{array}$ \\
(billion cedis)
\end{tabular}} \\
\hline & Urban & Rural & All & \\
\hline & \multicolumn{3}{|l|}{ (cedis) } & \\
\hline Taxes (TV License, property tax etc.) & 3,700 & 1,300 & 2,200 & 8.8 \\
\hline Contributions to self-help projects & 9,500 & 10,200 & 9,900 & 40.4 \\
\hline Weddings, dowry, funeral, etc. & 91,900 & 62,900 & 73,500 & 298.9 \\
\hline Gifts and presents (excluding remittances) & 36,700 & 28,900 & 31,800 & 129.3 \\
\hline Other miscellaneous expenditures & 21,500 & 12,500 & 15,800 & 64.3 \\
\hline Total & 163,300 & 115,800 & 133,200 & 541.7 \\
\hline
\end{tabular}

Source: GLSS 4 (Table 9. 27)

The estimated multiple linear regression equation of the relationship between a household's willingness to pay for a selected information delivery technology and the socio-economic characteristics of the households in each region is as follows:

$$
\text { 1. }(\text { WTP })_{\mathrm{ijt}}=\mathrm{a}_{0}+\mathrm{a}_{1}(\text { AGE })+\mathrm{a}_{2}(\text { EDUC })+\mathrm{a}_{3}(\text { MARS })+\mathrm{a}_{4}(\text { DEPEND })+\mathrm{a}_{5}(\text { EXPEND })+\mathrm{a}_{6}(\text { MEMBR })+\mathrm{U}_{\mathrm{i}},
$$

where (WTP) $)_{\mathrm{ijt}}$ is the willingness to pay by a household (i) in region (j) for information delivery technology (t), AGE is age of respondent measured in years, and EDUC is the educational level of respondent. The educational level was further broken down into two main levels of up to primary and above primary to reflect the low educational levels of women in rural households. MARS is the marital status of the respondent, and was measured using a dummy variable equal to 1 if respondent is married, and zero otherwise. DEPEND is the number of the dependents of respondent, EXPEND is the aggregate of all expenditures reported by the respondent measured in Ghana Cedis, and MEMBR is the membership of the respondent in a community organization. Membership was measured as a dummy variable, equal to 1 if the respondent belonged to a community organization and zero if otherwise. The term $U$ is a random error term assumed $\mathrm{N}\left(0, \sigma^{2}\right)$.

\section{Results}

Equation 1 was estimated for each of the three regions and the possible media of information transmission using the Newey-West estimator. This estimation technique helps to address one of the common problems when one uses crosssectional data. The socio-economic characteristics of households differ in important ways so unless the statistical procedure takes into account these variations; the estimated coefficients may not be efficient due to problems of heteroskedasticity and autocorrelation. The Newey-West estimation procedure takes into account the problems in using cross-section data to give consistent and efficient estimates. The results of the estimation procedures are presented below.

\section{Upper West Region}

Table 3a summarizes the effect of the selected factors on households' willingness to pay for information delivered via community radio in the Upper West Region of Ghana. The overall explanatory power of the model as measured by the R-square (Coefficient of determination) is low (12\%). Generally, R-squares obtained using cross-sectional data in statistical analysis tend to be low. The results show that older women (above 20 years) are willing to pay for information delivered via a community radio. This result is statistically significant at the $5 \%$ level. The results also show that women with more education (above primary level) are more willing to pay for information delivered via community radio. This result is also statistically significant at the $5 \%$ level. These outcomes are supported by the statistically significant (5\% level) relationship between membership in a community organization and the willingness to pay for information delivered via a community radio.

Table $3 \mathrm{~b}$ summarizes the results for households' willingness to pay for information via private radio. As in the case of the community radio, the overall explanatory power of the regression is low (11\%) but the expected signs on coefficients are as expected. Using expenditure as an income proxy, the results show that women with high incomes are 
more willing to pay for information delivered via private radio and the result is significant at the 5\% level. Membership in community organization is also statistically significant at the $10 \%$ level. As expected, women with a large number of dependents are not willing to pay for private radios. This is indicated by the negative sign on the coefficient even though the result is only mildly significant at the $10 \%$ level.

Table $3 \mathrm{c}$ summarizes the results for the willingness to pay for information delivered via an extension agent. The results are generally consistent with expectations. Women with more education are more willing to pay for information delivered via extension services. This result is statistically significant at the $5 \%$ level. In addition membership in a community organization is statistically significant, also at the $5 \%$ level. The overall conclusion one can draw is that education and membership in a community organization are important factors in explaining rural women's willingness to pay for information delivered via community radio and extension agents while, income is a critical factor in influencing willingness to pay for private radio.

Table 3a Regression Results for Households' Willingness to Pay for Community Radio Upper West Region

\begin{tabular}{lll} 
Variable & Coefficient & t-Statistic \\
\hline \hline Constant & 3613.51 & 2.54 \\
Age [Above 20] & 2025.88 & 2.44 \\
Married & 340.65 & 0.31 \\
Dependants & -104.32 & -0.76 \\
Educ. [Above Primary] & 3279.19 & 4.14 \\
Expenditure & -0.00 & -1.42 \\
Membership & 4089.84 & 3.92 \\
\hline \hline R-squared & 0.12 & $\mathrm{~N}=100$
\end{tabular}

Source: Survey Data, 2005

Table 3b Regression Results for Households' Willingness to Pay for Private Radio Upper West Region

\begin{tabular}{lll} 
Variable & Coefficient & t-Statistic \\
\hline \hline Constant & 13459.55 & 1.96 \\
Age [Above 20] & -10601.27 & -1.55 \\
Married & 6814.89 & 1.39 \\
Dependants & -631.28 & -1.52 \\
Educ. [Above primary] & -1709.22 & -0.76 \\
Expenditure & 0.01 & 2.16 \\
Membership & 13384.25 & 1.92 \\
\hline \hline R-squared & 0.11 & $\mathrm{~N}=100$
\end{tabular}

Source: Survey Data, 2005

Table 3c Regression Results for Households Willingness to Pay for Extension Agent Upper West Region

\begin{tabular}{lll} 
Variable & Coefficient & t-Statistic \\
\hline \hline Constant & 7219.27 & 6.98 \\
Age [Above 20] & 1021.40 & 1.19
\end{tabular}




\begin{tabular}{lll} 
Married & -100.99 & -0.16 \\
Dependants & -91.24 & -1.23 \\
Educ. [Above primary] & 1189.61 & 3.53 \\
Expenditure & -0.00 & -0.97 \\
Membership & 3225.93 & 3.42 \\
\hline \hline R-squared & 0.16 & $\mathrm{~N}=100$
\end{tabular}

Source: Survey Data, 2005

\section{Upper East Region}

The overall explanatory power of the regression for the Upper East Region is low as as compared to the case of the Upper West Region (cf. Tables 4a, 4b, and 4c). The highest R-square is 19\%. Here also, there are no major surprises given that cross-sectional data is being used in the regressions. There seems to be a consistent pattern in the results for this region in the sense that income seems to be the driving factor for the willingness to pay for information delivered via the three technologies under consideration in this paper. In all cases income is statistically significant at the 5\% level. The results also show that as expected, women with a large number of dependents are less likely to pay for information technologies. The theoretical exploration suggested that large households spend more on food and the basic necessities of life, especially health and shelter. It is not surprising that in all the technologies examined, there is a negative relationship between the number of dependents and households' willingness to pay for information. In all cases the estimated coefficient is significant at the $10 \%$ level.

Table 4a Regression Results for Households Willingness to Pay for Community Radio Upper East Region

\begin{tabular}{lll} 
Variable & Coefficient & t-Statistic \\
\hline \hline Constant & 2644.48 & 5.60 \\
Age [Above 20] & 597.10 & 1.67 \\
Marital Status & -51.419 & -0.17 \\
No. of Dependents & -159.88 & -3.01 \\
Educ [Up to Primary] & -339.16 & -1.04 \\
Educ.[Above Primary] & -188.24 & -0.67 \\
Expenditure & 0.000012 & 2.66 \\
Membership & 257.79 & 0.99
\end{tabular}

\begin{tabular}{lll}
\hline \hline R-squared & 0.16 & $(\mathrm{~N})=100$
\end{tabular}

Source: Survey Data, 2005

Table 4b Regression Results for Households Willingness to Pay for Private Radio Upper East Region

\begin{tabular}{lll} 
Variable & Coefficient & t-Statistic \\
\hline \hline Constant & 11718.43 & 2.87 \\
Age [Up to 20] & 1203.67 & 0.46 \\
Age [Above 20] & 2738.82 & 0.97 \\
Marital Status & 1422.34 & 0.52 \\
No. of Dependants & -763.68 & -1.94
\end{tabular}




\begin{tabular}{lll} 
Educ. [Above Primary] & 2107.70 & 0.76 \\
Expenditure & 0.0014 & 2.96 \\
Membership & 3785.22 & 1.58 \\
\hline \hline R-squared & 0.19 & $\mathrm{~N}=100$
\end{tabular}

Source: Survey Data, 2005

Table 4c Regression Results for Households Willingness to Pay for Extension Agent Upper East Region

\begin{tabular}{lll} 
Variable & Coefficient & t-Statistic \\
\hline \hline Constant & 5633.82 & 3.82 \\
Age [above 20] & 1910.57 & 1.66 \\
Married & -184.53 & -0.20 \\
Dependants & -266.84 & -1.84 \\
Educ. [Up to Primary] & -604.51 & -0.61 \\
Educ. [Above Primary] & 66.42 & 0.07 \\
Expenditure & 0.00042 & 2.95 \\
Membership & 1180.72 & 1.73 \\
\hline \hline R-squared & 0.18 & $\mathrm{~N}=100$
\end{tabular}

Source: Survey Data, 2005

\section{Northern Region}

The summary of regression results for the Northern Region of Ghana is shown in Tables 5a, 5b, and 5c. As in the case of the other regions, the explanatory power of the model is quite low, between $7 \%$ and $17 \%$. The signs and statistical significance of most of the factors are not consistent with expectations. Probably the strongest factor is membership in a community organization which is statistically significant and consistent with expectations in the case of women's willingness to pay for information delivered via community radio. Table 5a shows that married women are not willing to pay for information delivered via community radio. There could be several reasons explaining this result, the most plausible being the cost of maintaining a two-person versus one-person household. Consistent with expectation, the results show that women who are members of a community organization are willing to pay for information delivered via community radio (Table 5a).

The results show that younger women (up to age 20) are willing to pay for information delivered via private radio. The estimated coefficient is significant at the $5 \%$ level (Table 5b). This same group of younger women are not willing to pay for information delivered via an extension agent, an outcome that is statistically significant at the $10 \%$ level (Table $5 \mathrm{c}$ ). Women who have been educated above primary school education are willing to pay for information delivered by an extension agent, an outcome that is statistically significant at the 5\% level (Table 5c).

Table 5a: Regression Results for Households Willingness to Pay for Community Radio Northern Region

\begin{tabular}{lll} 
Variable & Coefficient & t-Statistic \\
\hline \hline Constant & 3653.83 & 15.48 \\
Age [Up to 20] & -320.01 & -1.13 \\
Age [Above 20] & -24.78 & -0.18 \\
Married & -567.79 & -3.26 \\
Dependants & -49.76 & -0.87
\end{tabular}




\begin{tabular}{|c|c|c|}
\hline Education [Above Primary] & -556.64 & -1.48 \\
\hline Expenditure & $4.61 \mathrm{E}-05$ & 0.85 \\
\hline Membership & 510.81 & 2.17 \\
\hline R-squared & 0.14 & $\mathrm{~N}=100$ \\
\hline Source: Survey Data, 2005 & & \\
\hline $\begin{array}{l}\text { Table 5b Regression Result } \\
\text { Northern Region }\end{array}$ & Households & ness to Pay $f$ \\
\hline Variable & Coefficient & t-Statistic \\
\hline Constant & 22601.71 & 9.23 \\
\hline Age[Up to 20] & 5275.66 & 2.82 \\
\hline Age [Above 20] & -49.36 & -0.045 \\
\hline Married & 1858.81 & 1.16 \\
\hline Dependants & 126.23 & 0.49 \\
\hline Educ. [Above Primary] & 1468.45 & 0.85 \\
\hline Expenditure & 0.00047 & 1.83 \\
\hline Membership & 906.08 & 0.68 \\
\hline R-squared & 0.076 & $\mathrm{~N}=100$ \\
\hline
\end{tabular}

Source: Survey Data, 2005

Table 5c: Regression Results for Households Willingness to Pay for Extension Agent Northern Region

\begin{tabular}{lll} 
Variable & Coefficient & t-Statistic \\
\hline \hline Constant & 6140.82 & 7.89 \\
Age [Up to 20] & -2376.81 & -1.99 \\
Age [Above 20] & 4.65 & 0.0082 \\
Married & -0.25 & -0.00038 \\
Dependants & 78.27 & 0.86 \\
Educ. [Above primary] & 5038.58 & 2.19 \\
Expenditure & $-8.85 \mathrm{E}-05$ & -1.44 \\
Membership & 600.94 & 1.38 \\
\hline \hline R-squared & 0.17 & $\mathrm{~N}=100$
\end{tabular}

Source: Survey Data, 2005

\section{Conclusion}

This study used rural household survey data collected from three administrative regions in Ghana to examine rural women's willingness to pay for information delivered via three technologies - community radio, private radio, and extension agents. The primary objective in the study was to identify the critical factors to consider in planning and policy design in using ICT to provide information to empower rural women. While there were nontrivial regional 
variations, the overall results from this study point to household expenditures (used as proxy for income), household education, and membership in community organizations as the principal factors influencing rural women's willingness to pay for the various technologies used in information delivery to women in rural areas in Ghana. The overriding conclusion that emerges from this study is the need to examine ICT use in empowering rural women within a 'holistic' context. No single socio-economic factor emerged as the 'magic bullet' in planning policies and programmes to introduce ICT use in information delivery to rural women. Likewise, no single information delivery technology emerged as the technology to use in delivering information to rural women.

Despite the lack of consistency in the regression results, several important policy and planning options are suggested by the results of this study. Because of the significance of income in ICT use in rural empowerment, there is a need to cast rural empowerment policies and programs within the broader poverty reduction policies of the government and also within the attainment of the Millennium Development Goals (MDGs). If the Government intends to focus on the attainment of the MDGs, then the education factor and the importance of community cohesiveness become more critical as shown by the statistical results.

Focusing particularly on the income factor, there are at least two important issues to address. First, the relationship between ICT use and income must be seen as bi-directional. While high incomes make it possible for rural women to pay for the information delivery technology of choice, the delivered information, in turn, is intended to empower women to be able to make those decisions that would improve their welfare and incomes. A second implication of the statistical significance of the income factor is the need to broaden policies to enhance the many possible sources of income available to rural women. Even though the popular view has been to focus on agriculture as the primary source of raising incomes of rural women, the survey results point to a need to broaden the scope of an income policy in rural areas to tap into non-agricultural sources. 


\section{References}

Abbey-Mensah, E. (2001). Expert consultation on rural women and distance learning: Regional strategies. Retrieved November 12, 2004 from $\mathrm{http}: / / w w w . f a o . o r g / s d / 2003 / P E 12033 a$ en.htm http://www.fao.org/sd/ruralradio/en/index.html

Anan, K. (2002). UN General Assembly Report. Retrieved December 14, 2004 from http://daccessdds.un.org/doc/UNDOC/GEN/N02/516/01/PDF/N0251601.pdf?OpenElement; http://www.un.org/ga/57/document.htm

Boadu, F.O. (1993). Contingent valuation for household water in rural Ghana. Journal of Economics, 43(3).

GLSS 4 (2000). Ghana Living Standards Survey: Report of the fourth round, Ghana Statistical Service, Accra.

GPRS (2003, February 4). Ghana Poverty Reduction Strategy 2003 -2005 - An agenda for growth and prosperity. Retrieved September 16, 2004 from http://poverty.worldbank.org/files/Ghana PRSP.pdf

Haba, S. (2004). Factors influencing the willingnes to pay for agricultural information delivery technologies by small agribusinesses: Evidence from the Abahuzamugambi Coffee Growers' Cooperative of Maraba-Butare, Rwanda. Unpublished masters' dissertation, Texas A\&M University, Texas.

Kwapong, O. A. T. F. (2005). The use of ICTs for empowerment of rural women in Ghana. Unpublished doctoral dissertation, University of Ghana, Accra.

Tan, J., Lee, K.H., \& Mingat, A. (1984). User charges for education: The ability and willingness to pay in Malawi. Staff Working Paper 661, Washington, D.C: The World Bank.

Thobani, M. (1983). Efficiency and equity implications of user charges in social sector service: The financing of education in Malawi. Staff Working Paper 572, Washington, D.C: The World Bank.

World Bank (2003). Development Data Group. Retrieved May 11, 2004 from http://devdata.worldbank.org/ 